\title{
Vibration Analysis of Partially Cracked Symmetric Laminated Composite Plates Using Grey-Taguchi
}

\author{
Ajay Kumar Verma ${ }^{1}$, Vikky Kumhar ${ }^{1}$, Manoj Verma ${ }^{2, *(\mathbb{D})}$, Vishal Rastogi ${ }^{1}{ }^{\mathbb{D}}$ \\ 1 Department of Mechanical Engineering, FET-SSGI, Shri Shankaracharya Technical Campus, Bhilai, 490020 Chhattisgarh, \\ India \\ 2 Department of Energy \& Environmental Engineering, UTD-Chhattisgarh Swami Vivekananda Technical University, Durg, \\ Chhattisgarh, 491107 India \\ * Correspondence: e manojverma.csvtu@gmail.com (M.V.);
}

Scopus Author ID 36877094800

Received: 14.08.2021; Revised: 18.09.2021; Accepted: 22.09.2021; Published: 3.10.2021

\begin{abstract}
Nowadays, the demand for carbon-boron boron-based composites has tremendously increased in the aerospace and automotive industries due to their lightweight and high strength-weight ratio. Hence, it is necessary to study the vibrational behavior of the carbon-boron matrix. The stacking sequences, fiber orientation, crack size, and length-width ratio has all been studied at three levels. A mathematical model has been developed using classical laminated plate theory to evaluate the natural frequency for two boundary conditions; first, all sides were supported (SSSS), second, two adjacent sides clamped, and the other two were simply supported (CCSS). Grey relation analysis has also been applied to optimize the parameters.
\end{abstract}

Keywords: laminated composite plate; SSSS; CCSS; vibration; grey relational analysis; Taguchi method.

(C) 2021 by the authors. This article is an open-access article distributed under the terms and conditions of the Creative Commons Attribution (CC BY) license (https://creativecommons.org/licenses/by/4.0/).

\section{Introduction}

Plate structures are an integral part of the engineering industry, and their application ranges from shipbuilding, aerospace, automobile to process plants. When combined in the formation of a third useful material, two or more materials are called composite material. With the high strength-to-weight ratio and research in understanding their mechanics, composite plates are seen as a substitute for metal plates, especially in the automotive and aerospace industries.

The Classical Plate Theory (CLPT), which extends the Classical Plate Theory (CPT) to include the effects of aircraft strains, is disregarded. The increased differing elastic properties between fiber filaments and matrix materials lead to the large proportion of cross shear deformations developed in the plane of young modules for most composite laminates, which are considerably more pronounced for laminated plates as compared to isotropic because of their transversal shear deformations [1-3]. The Taguchi method optimized performance through control settings and lowered system performance susceptibility to variation sources [4, 5]. The grey relational analysis based on the notion of the grey theory is used to resolve complex connections between the multiple answers. The average grey relational grade for analyzing the relational degree of the multiple answers is the grey relational grade [6-13]. This technique uses S/N (Signal-Noise) ratio and ANOVA (Analysis of Variance) to obtain the 
optimum combination of process parameters and significant parameters [14-16]. The analytical approach has been made for vibration analysis of plates considering crack [17-21].

The objective of the present study is to familiarize the application of grey relational analysis in choosing optimal conditions and a combination of multi-performance characteristics, namely stacking sequence, crack length, the volume of fraction, and lengthwidth ratio. The setting of process parameters is found optimal using the Taguchi design data method based on Grey analysis. The most effective factor and the order of significance of the governable factors to the multi-performance appearances in the manufacturing process were obtained.

\section{Materials and Methods}

\subsection{Mathematical formulation and methodology.}

\subsubsection{Formulation of frequency response.}

Different relationships are formed under in-plane loads such as bend, twisting moment, the axial and shearing force for a laminated hybrid composite plate. In these relationships, CLPT is applied. The following assumptions [17] are taken in the CLPT: Relationship development: Individual laminate is orthotropic, orthotropic, and homogeneous; a straight line to the middle surface during deformation remains straights and upright, the laminate is tinny and is only loaded into the plane (planar stress), each laminate shows elastic behavior, and there is no slip between lamina boundaries.

With the classical Kirchhoff's assumptions, the laminate behaves like a single layer with special properties that constitute a structural element. The stresses normal to the mid-plane are assumed to be small and are neglected. The plate thickness is very small than its length and width. Each lamina is orthotropic, linear elastic, and of constant thickness.

There's no force in the body. Rotating inertia is not taken into account. The equilibrium equations for transverse vibrations of symmetric angle ply laminate (for transverse deflection ' $w$ ' and ' $\rho$ ' for density) [22], which lead to,

$D_{11} \frac{\partial^{4} w}{\partial x^{4}}+4 D_{16} \frac{\partial^{4} w}{\partial x^{3} \partial y}+2\left(D_{12}+2 D_{66}\right) \frac{\partial^{4} w}{\partial x^{2} \partial y^{2}}+4 D_{26} \frac{\partial^{4} w}{\partial x \partial y^{3}}+D_{22} \frac{\partial^{4} w}{\partial y^{4}}=-\rho h \frac{\partial^{2} w}{\partial t^{2}}$

where, the bending stiffness $[D]=\left[\begin{array}{lll}D_{11} & D_{12} & D_{16} \\ D_{12} & D_{22} & D_{26} \\ D_{16} & D_{26} & D_{66}\end{array}\right]$.

For symmetric ply laminate angle, the bending width of the coupling stiffness matrix $[B]=\left[\begin{array}{lll}B_{11} & B_{12} & B_{16} \\ B_{12} & B_{22} & B_{26} \\ B_{16} & B_{26} & B_{66}\end{array}\right]$ is zero. Also, because the control equations are unconnected, the extension rigidity matrix $[\mathrm{A}]$ is unimportant.

Under the application of the lateral load 'p', summing up the lateral forces along zdirection and applying moment equilibrium about $\mathrm{x}$ and $\mathrm{y}$ axes, one obtains

$$
\frac{\partial^{2} M_{x}}{\partial x^{2}}+2 \frac{\partial^{2} M_{x y}}{\partial x \partial y}+\frac{\partial^{2} M_{y}}{\partial y^{2}}+\frac{\partial^{2} M_{y c}}{\partial y^{2}}+\rho h \frac{\partial^{2} w}{\partial t^{2}}=-p
$$

The moment-curvature relation is given by 


$$
\left[\begin{array}{c}
M_{x} \\
M_{y} \\
M_{x y}
\end{array}\right]=\left[\begin{array}{lll}
D_{11} & D_{12} & D_{16} \\
D_{12} & D_{22} & D_{26} \\
D_{16} & D_{26} & D_{66}
\end{array}\right]\left[\begin{array}{c}
-\frac{\partial^{2} w}{\partial x^{2}} \\
-\frac{\partial^{2} w}{\partial y^{2}} \\
-2 \frac{\partial^{2} w}{\partial x y^{2}}
\end{array}\right]
$$

where bending stiffness ' $\mathrm{D}$ ' is described in Eqn. 4:

$$
D_{i j}=\frac{1}{3} \sum_{k=1}^{n}\left[\left(\bar{Q}_{i j}\right)\right]_{k}\left(h_{k}^{3}-h_{k-1}^{3}\right) i=1,2,6 ; j=1,2,6 .
$$

and the transformed reduced stiffness $\left(\bar{Q}_{i j}\right)$ can be obtained in terms of elasticity constants [22]. Using Eqns. $3 \&$ 2, the governing equation becomes

$$
D_{11} \frac{\partial^{4} w}{\partial x^{4}}+4 D_{16} \frac{\partial^{4} w}{\partial x^{3} \partial y} 2\left(D_{12}+2 D_{66}\right) \frac{\partial^{4} w}{\partial x^{2} \partial y^{2}}+4 D_{26} \frac{\partial^{4} w}{\partial x \partial y^{3}}+D_{22} \frac{\partial^{4} w}{\partial y^{4}}=-\rho h \frac{\partial^{2} w}{\partial t^{2}}+\frac{\partial^{2} M_{y c}}{\partial y^{2}}+p \ldots
$$

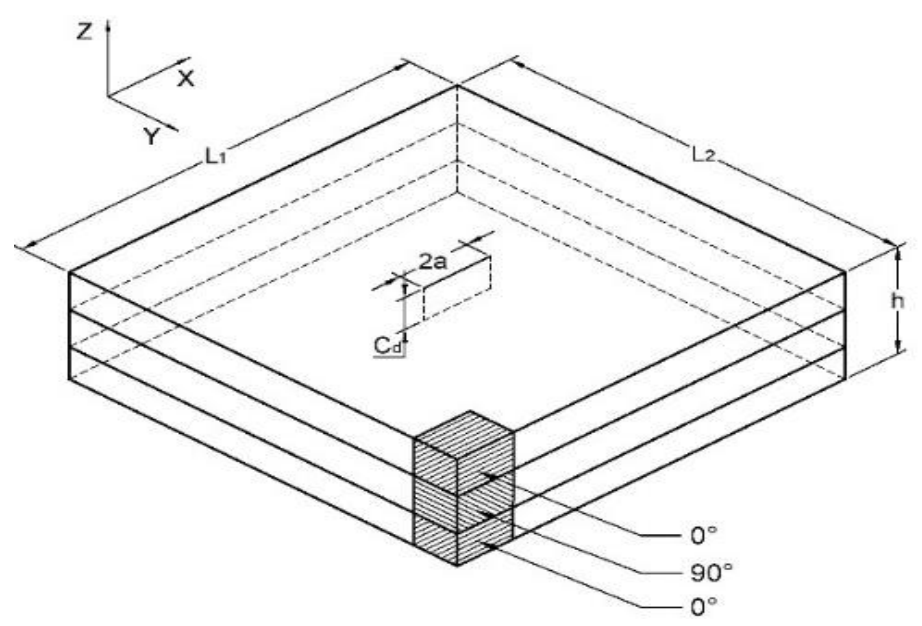

(a)

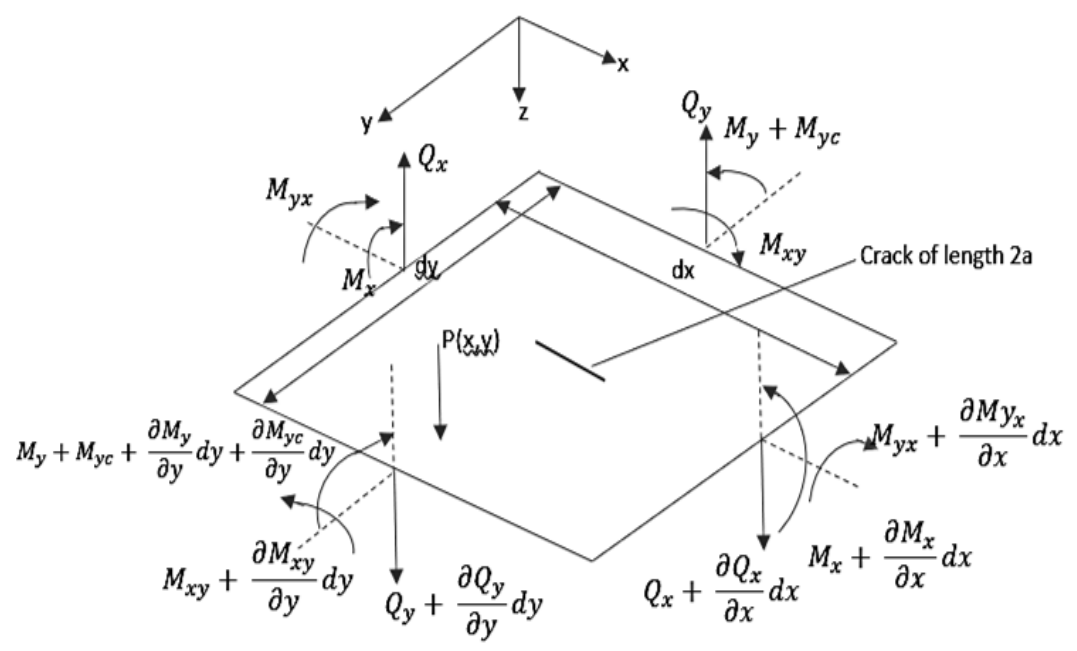

(b)

Figure 1. (a) Partially cracking symmetric cross-section laminated platforms (b) Differential elements of plates showing intermediate moments and inner forces.

Fig. 1 shows the moments per unit length acting on the differential element of the midplane of the laminated plate for which the equilibrium of moments and transverse forces is applied. $M_{x}$ and $M_{y}$ are the bending moments, $M_{x y}=M_{y x}$ are the twisting moments. $M_{y c}$ is the moment per unit length due to the crack of length $2 \mathrm{a}$. The in-plane forces acting on the midplane are considered next for equilibrium. The membrane or in-plane forces usually occur due to support constraints to in-plane displacements, adjacent structures, or pre-stressing. The 
amount of these forces depends on the edge conditions and is naturally more for the clamped plate. The recent literature [18-20] on the vibration of cracked isotropic and orthotropic plates shows that adding in-plane forces to the governing equation of transverse vibration of the plate makes the system non-linear. It shows that the summation of such forces along the thickness of the plate results in a lateral force added to the governing equation. In the present work, to study such a non-linear effect on the vibrations of the laminated plate, the equilibrium of inplane forces along the $\mathrm{z}$-axis is considered apart from the lateral shear force and moment equilibrium seen in Eqn. 2. Fig. 2 shows the in-plane forces on the plate differential element for an arbitrary boundary condition.

A supplementary in-plan power $f_{y c}$ to the simplified line spring model has been considered as traditional [21]. Fig. 2 shows that the combination of membrane forces leads to a lack of body forces;

$$
\sum F_{z \text { axis }}=f_{x} \frac{\partial^{2} w}{\partial x^{2}}+f_{y} \frac{\partial^{2} w}{\partial y^{2}}+2 f_{x y} \frac{\partial^{2} w}{\partial x \partial y}+f_{y c} \frac{\partial^{2} w}{\partial y^{2}}
$$

where the membrane forces of $f_{x}, f_{y}$ are the $\mathrm{x}$ and y-axis, $f_{y c}$ is created by a fracture in the plate center. The in-plane forces $\left(f_{y}\right.$ and $\left.f_{x y}\right)$ along the y axis were overlooked by modeling for isotropic plates due to a y-axis crack [18]. These forces are also overlooked because of the discontinuity on the axis of $y$ in the present work.

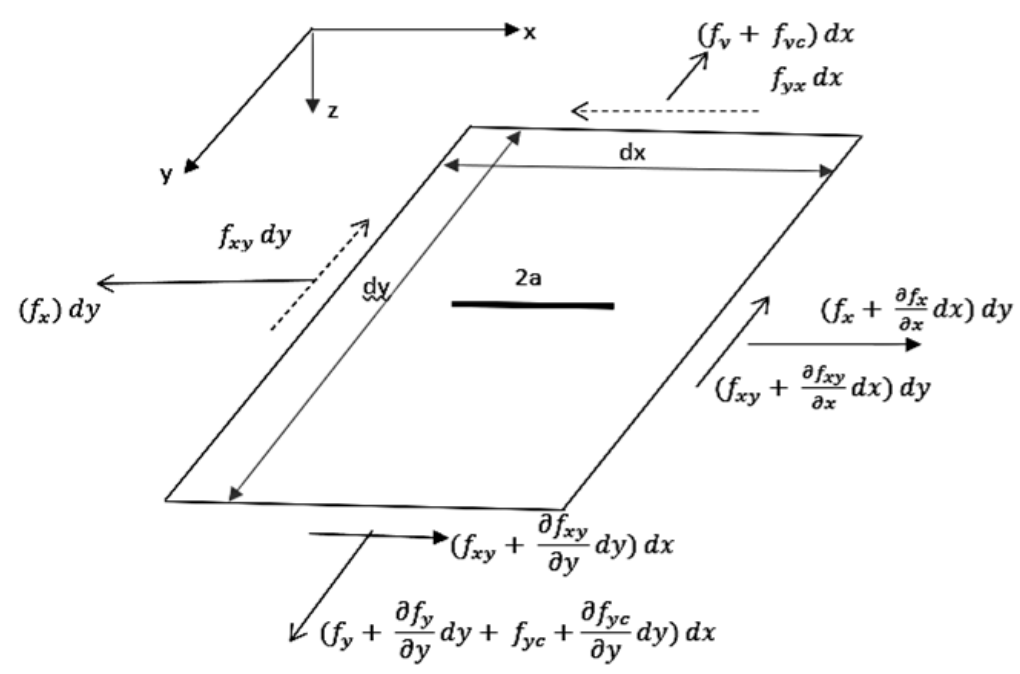

Figure 2. In-plane forces on the mid-plane for equilibrium.

For the crack length ' $2 \mathrm{~b}$ ' the forces $\left(f_{x}\right.$ and $\left.f_{x y}\right)$ are to be neglected and the force $f_{x c}$ has to be considered. Thus, after neglecting the forces along the y-axis and adding Eqns. $5 \&$ 6 one obtains

$D_{11} \frac{\partial^{4} w}{\partial x^{4}}+4 D_{16} \frac{\partial^{4} w}{\partial x^{3} \partial y} 2\left(D_{12}+2 D_{66}\right) \frac{\partial^{4} w}{\partial x^{2} \partial y^{2}}+4 D_{26} \frac{\partial^{4} w}{\partial x \partial y^{3}}+D_{22} \frac{\partial^{4} w}{\partial y^{4}}=-\rho h \frac{\partial^{2} w}{\partial t^{2}}+\frac{\partial^{2} M_{y c}}{\partial y^{2}}+$ $f_{x} \frac{\partial^{2} w}{\partial x^{2}}+f_{y c} \frac{\partial^{2} w}{\partial y^{2}}+p$

2.1.2. Formulation of the crack terms $M_{y c}$ and $f_{y c}$.

The presence of a crack in plated structure affects the local stiffness, and its mechanical dynamics have always been an area of concern not only for designers but also for the online detection of cracks without dismantling the structure. Literature shows that the presence of cracks in vibrating elements can cause sudden failure. For the laminated plate, it is still more 
important to analyze the effect of crack as the crack penetrates through various layers (with different materials) of the laminate. The essence of the Line Spring Model (LSM) based on Kirchhoff's bending theory for plates is the relationship between the stress at the crack location and the stress state at the far edges of the plate.

This work expands and adapts the simple LSM for crack terminology available in the literature [18] to the layered nature of the platform. An LSM image is illustrated in Fig. 3. So the relation between stress at the crack location and at the far ends of the plate for a laminate with a partial crack of length 2 a might be suggested as,

$$
M_{y c}=\frac{2 a}{3\left(\frac{C_{b t}}{6}+C_{b b}\right)\left(3+v_{x}\right)\left(1-v_{x}\right) h+2 a}\left(-D_{12} \frac{\partial^{2} w}{\partial x^{2}}-D_{22} \frac{\partial^{2} w}{\partial y^{2}}-D_{26} \frac{\partial^{2} w}{\partial x \partial y}\right)
$$

Similarly, the relation for the in-plane force at the crack location and the far sides of the plate can be proposed as

$$
f_{y c}=\frac{2 a}{3\left(6 C_{b t}+C_{t t}\right)\left(1-v_{x}^{2}\right) h+2 a} f_{y}
$$

For the crack of length $2 b$, the above relations become

$$
\begin{gathered}
M_{x c}=\frac{2 b}{3\left(\frac{C_{b t}}{6}+C_{b b}\right)\left(3+v_{y}\right)\left(1-v_{y}\right) h+2 a}\left(-D_{11} \frac{\partial^{2} w}{\partial x^{2}}-D_{12} \frac{\partial^{2} w}{\partial y^{2}}-D_{16} \frac{\partial^{2} w}{\partial x \partial y}\right) \\
f_{y c}=\frac{2 b}{3\left(6 C_{b t}+C_{t t}\right)\left(1-v_{y}\right) h+2 a} f_{y}
\end{gathered}
$$

The presence of Poisson's ratio $v_{x}$ in Eqns. $6 \& 7$ can be justified because the stiffness involved in these equations depends on Poisson's ratio. Similar reasoning applies to Poisson's ratio $v_{y}$ in Eqns. 8 \& 9 .

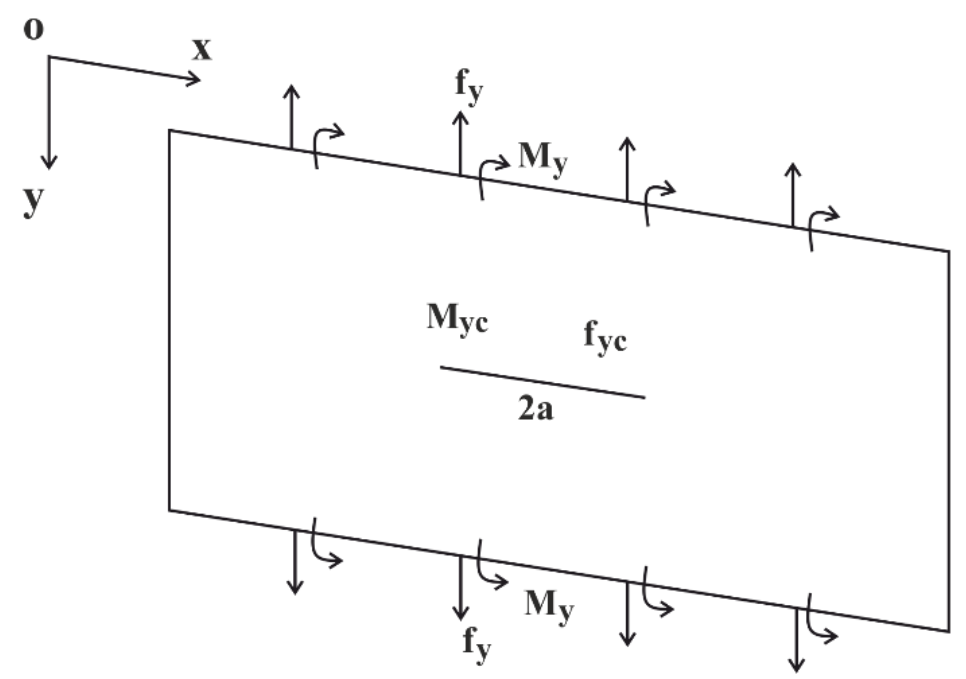

Figure 3. Representation of bending and stretching force effects as per Line Spring Model.

Eqns. $8 \& 9$ are to be added to the governing equation with a negative sign as there is a reduction in stiffness due to crack, and literature $[18,21]$ shows such a phenomenon for isotropic and orthotropic plates. Thus, using Eqns. (8) \& (9), the governing equation of cracked plate can be recast as,

$D_{11} \frac{\partial^{4} w}{\partial x^{4}}+4 D_{16} \frac{\partial^{4} w}{\partial x^{3} \partial y}+2\left(D_{12}+2 D_{66}\right) \frac{\partial^{4} w}{\partial x^{2} \partial y^{2}}+4 D_{26} \frac{\partial^{4} w}{\partial x \partial y^{3}}+D_{22} \frac{\partial^{4} w}{\partial y^{4}}=-\rho h \frac{\partial^{2} w}{\partial t^{2}}-$
$\frac{2 a}{3\left(\frac{C_{b t}}{6}+C_{b b}\right)\left(3+v_{x}\right)\left(1-v_{x}\right) h+2 a} \frac{\partial^{2}\left(-D_{12} \frac{\partial^{2} w}{\partial x^{2}}-D_{22} \frac{\partial^{2} w}{\partial y^{2}}-D_{26} \frac{\partial^{2} w}{\partial x \partial y}\right)}{\partial y^{2}}+f_{x} \frac{\partial^{2} w}{\partial x^{2}}-\frac{2 a}{3\left(6 C_{b t}+C_{t t}\right)\left(1-v_{x}\right) h+2 a} f_{y} \frac{\partial^{2} w}{\partial y^{2}}+p$

Berger, in 1955 obtained the deflection of the plate by neglecting the second invariant of mid-plane strains and shows that the form of in-plane forces works well for simply supported 
and clamped boundary conditions. Such a treatment of in-plane forces is vivid in literature $[18,19]$. The formulation for two perpendicular cracks and also for orthotropic plates [21]. Thus in-plane forces can be expressed in terms of mid-surface strains $\left(\epsilon_{x}\right.$ and $\left.\epsilon_{y}\right)$ as

$$
\begin{aligned}
& f_{x}=A_{11} \epsilon_{x}+A_{12} \epsilon_{y} \\
& f_{y}=A_{12} \epsilon_{x}+A_{22} \epsilon_{y}
\end{aligned}
$$

After expressing the mid-surface strains in terms of deflection, it can be shown that

$$
\begin{aligned}
& f_{x}=A_{11}\left(\frac{\partial u}{\partial x}+\frac{1}{2}\left(\frac{\partial w}{\partial x}\right)^{2}\right)+A_{12}\left(\frac{\partial v}{\partial y}+\frac{1}{2}\left(\frac{\partial w}{\partial y}\right)^{2}\right) \\
& f_{y}=A_{12}\left(\frac{\partial u}{\partial x}+\frac{1}{2}\left(\frac{\partial w}{\partial x}\right)^{2}\right)+A_{22}\left(\frac{\partial v}{\partial y}+\frac{1}{2}\left(\frac{\partial w}{\partial y}\right)^{2}\right)
\end{aligned}
$$

Multiplying Eqns. (14) \& (15) by $d x d y$, integrating over plate area and imposing the condition that the in-plane deflections $\mathrm{u}$ and $\mathrm{v}$ vanish at the plate boundaries due to symmetry, one obtains

$$
\begin{aligned}
& f_{x}=A_{11} \frac{1}{2 L_{1} L_{2}}\left\{A_{11} \int_{0}^{L_{1}} \int_{0}^{L_{2}}\left(\frac{\partial w}{\partial x}\right)^{2}+A_{12} \int_{0}^{L_{1}} \int_{0}^{L_{2}}\left(\frac{\partial w}{\partial x}\right)^{2}\right\} d x d y \\
& f_{y}=\frac{1}{2 L_{1} L_{2}}\left\{A_{12} \int_{0}^{L_{1}} \int_{0}^{L_{2}}\left(\frac{\partial w}{\partial x}\right)^{2}+A_{22} \int_{0}^{L_{1}} \int_{0}^{L_{2}}\left(\frac{\partial w}{\partial x}\right)^{2}\right\} d x d y
\end{aligned}
$$

Eqns. $16 \mathrm{a} \& 16 \mathrm{~b}$ in the form of the in-plane forces that can be used in Eqn. 14.

\subsubsection{Frequency response.}

One of the perturbation methods, the method of multiple scales, is very well known by the efforts of Nayfeh and has been described vividly in literature [23, 24]. Researchers have recently used it to study the frequency response of isotropic and orthotropic rectangular plates $[18,19]$. The present work extends this to the case of partially cracked laminate can be restated as

$$
\ddot{\varphi}_{m n}(t)+\omega^{2} \varphi_{m n}(t)+\delta_{m n} \varphi_{m n}^{3}(t)=\lambda_{m n} p_{0}(t)
$$

where, $\omega^{2}=\frac{K_{m n}}{M_{m n}}, \quad \delta_{m n}=\frac{R_{m n}}{M_{m n}}, \quad \lambda_{m n}=\frac{X_{m}\left(x_{0}\right) Y_{n}\left(y_{0}\right)}{M_{m n}}, \quad P_{m n}=X_{m}\left(x_{0}\right) Y_{n}\left(y_{0}\right) p_{0}(t)$ and $\left(x_{0}, y_{0}\right)$ is the point of application of the load $p_{m n}$.

Idealizing the non-linear damping to weak classical linear viscous damping with damping factor $\mu$ and letting the external load as harmonic, $p_{0}(t)=p_{0} \cos \theta_{m n}(t)$, the equation of the racked laminate becomes

$$
\ddot{\varphi}_{m n}(t)+2 \mu \dot{\varphi}_{m n}(t)+\omega^{2} \varphi_{m n}(t)+\delta_{m n} \varphi_{m n}^{3}(t)=\lambda_{m n} p_{0} \cos \theta_{m n}(t)
$$

Let us consider the natural vibration of an especially orthotropic plate. For periodic motion, assuming

$$
\omega_{o}(x, y, t)=\bar{\omega}_{0}(x, y) e^{i \omega t}
$$

where, $i=\sqrt{-1}$ and $\omega$ is natural frequency.

There are many other latest research articles about different composite materials and vibrational analysis, which were studied for this work [25-45].

\subsubsection{Grey relational analysis.}

Multi-response optimization is primary to optimize various process performance features and any process/product performance with multi-performance features. To achieve this, there is a need to collect multi-performance features to get the equivalent single objective function. The purpose mentioned above function is required to be optimized. This function uses Grey Rational Analysis (GRA) to integrate multi-evaluated output characteristics (stacking 
sequences) into an equivalent single performance index called OGI (Overall Grey Index). To avoid different units, the data diversity range and conflict in criteria requirements (Staking Sequences: high-better-better, i.e., HB; right: lower-is-better, i.e., LB), calculation or test data has been first generalized/normalized [11-14].

Higher is better

$$
y_{i}^{*}(i)=\frac{y_{i}(i)-\min _{i=1}^{n}\left[y_{i}(i)\right]}{\max _{i=1}^{n}\left[y_{i}(i)\right]-\min _{i=1}^{n}\left[y_{i}(i)\right]}
$$

Lower is better

$$
y_{i}^{*}(j)=\frac{\max _{i=1}^{n}\left[y_{i}(j)\right]-y_{i}(j)}{\max _{i=1}^{n}\left[y_{i}(j)\right]-\min _{i=1}^{n}\left[y_{i}(j)\right]}
$$

The variance or difference among the normalized value and reference value has been calculated using the following Eqn. 22:

$$
\Delta_{0 i}(j)=\left|y_{0}^{*}(j)-y_{i}^{*}(j)\right|
$$

After that, individual grey relation coefficient (Tables $3 \& 5$ ) was calculated for the characteristics above using the following Eqns. 23:

$$
G C_{0 i}(j)=\frac{\min _{i=1}^{n} \min _{j=1}^{k} \Delta_{0 i}(j)+\lambda \times \max _{i=1}^{n} \max _{j=1}^{k} \Delta_{0 i}(j)}{\Delta_{0 i}(j)+\lambda \times \max _{i=1}^{n} \max _{j=1}^{k} \Delta_{0 i}(j)}
$$

where, $\lambda(0 \leq \lambda \leq 1)$ is known as the distinguishing coefficient. A smaller value of $\lambda$; accounts for higher distinguishability.

To get a single equivalent output, the overall grey relation index (OGI) (Table $3 \& 5$ ) has been assessed using the Eqns. 24:

$$
\Gamma_{0 i}=\sum_{j=1}^{k}\left[w(j) \times G C_{0 i}(j)\right], \sum_{J=1}^{K} w(J)=1
$$

where, $w(j)$ is the weight of $j^{t h}$ response variable. $\Gamma_{0 i}$ is the grey relational degree, which represents the correlation between $i^{\text {th }}$ ordering and the reference order.

\subsubsection{Taguchi method.}

The Taguchi approach was developed by Genichi Taguchi in the 1940s by introducing a new method to optimize engineering or real-life experimentation. Changes in the quality appearances of the product response of the factor presented in the experimental design indicate the desired effect. Under the test, due to the effect of quality characteristics, the effect of external factors is known as noise. A proper loss function must first be built with its constant value, which is not always affordable and easy if the loss work is to be used as a qualifying character. When Taguchi suggests the use of $\mathrm{S} / \mathrm{N}$ ratios to measure distracted quality attributes with the desired value, the results of the test run are transformed to a signal-to-noise ratio $(\mathrm{S} / \mathrm{N})$. The $\mathrm{S} / \mathrm{N}$ ratio is taken into account based on an $\mathrm{S} / \mathrm{N}$ analysis, and one metric changes for each level of the process variables. Regardless of the target quality features, the results establish the highest achievable $\mathrm{S} / \mathrm{N}$ ratio in any experiment. The high value of $\mathrm{S} / \mathrm{N}$ shows the signal is very high, and the noise signal ratio is utilized as the quality of choice in Taguchi's optimization approach $[10-12,14]$. The distinct $\mathrm{S} / \mathrm{N}$ ratios are nominal; the best, the smaller, the better and, the greater, the better.

Nominal the best feature: In this feature, the nearer to the target value, the better. Whether the deviation exceeds or is below the target value does not matter. The deviation is quadratic according to this method.

The formulation for these characteristics is:

$$
\frac{s}{N}=10 \log \frac{y}{S_{y}^{2}}
$$


where, $S_{\mathcal{y}}^{2}=$ variance of y (observed data).

Smaller the better characteristic: the smaller, the better method held when a concern desires smaller value. As the value gets larger, the loss suffered raises. The formulation for these characteristics is:

$$
\frac{S}{N}=-10 \log \frac{1}{n} \sum \mathcal{Y}^{2}
$$

where, $\mathcal{Y}=$ average of observed values and $\mathrm{n}=$ number of observations.

Larger the better: bigger is better if a corporation wants higher characteristic values. The participation of employees and customer acceptance rates are two examples. The larger, the less the quality loss function, is the more characteristic. These characters are formulated as follows:

$$
\frac{S}{N}=-10 \log \frac{1}{n} \sum \frac{1}{y^{2}}
$$

Present work design of experiment (DOE) has been taken according to mixed level $\mathrm{L}_{27}$ orthogonal array (Table 1). To decide DOE test run number, the selection ahead of the orthogonal array is based on the number of the independent variable and the number of factors for each independent variable. In this study, $\mathrm{L}_{27}$ arrays have been used for the best results to be obtained. The crack length ratio, the volume of fraction, and the length-width ratio have been selected as control process parameters.

Table 1. Setting parameter and their levels.

\begin{tabular}{l|c|c|c|c} 
Level & Detail & Level 1 & Level 2 & Level 3 \\
\hline $\mathbf{a} / \mathbf{L}_{1}$ & Crack length ratio & 0.00 & 0.03 & 0.05 \\
\hline $\mathbf{V F}$ & Volume of Fraction & $0.6 / 0.6$ & $0.5 / 0.6$ & $0.4 / 0.6$ \\
\hline $\mathbf{L}_{\mathbf{2}} / \mathbf{L}_{\mathbf{1}}$ & Length-width ratio & 1.0 & 1.5 & 2.0
\end{tabular}

\section{Results and Discussion}

The DOE method permits the modeling and analysis of the effect of process variables on the response variables. The presence of a crack in rectangular plated structures subjected to dynamic forces can cause changes in dynamic behavior. Such analysis is evident in literature for isotropic and orthotropic plates $[15,16]$. The present work analyzes the effect of partial crack on the vibration behavior of symmetric laminates. The top and bottom layers are made up of carbon fibers in an epoxy matrix; the middle layer is boron fibers with epoxy. The elastic material properties are; carbon $(\mathrm{Ec}=220 \mathrm{GPa})$, Epoxy $(\mathrm{Ee}=3.6 \mathrm{GPa})$, boron $(\mathrm{Eb}=208 \mathrm{Gpa})$, the density of the laminate is taken as $2000 \mathrm{~kg} / \mathrm{m}^{3}$, whereas the Poisons ratios are $v_{c}=0.22, v_{b}$ $=0.23, v_{e}=0.35$.

Here, all the three layers have the same thickness (each layer $6 \mathrm{~mm}$ thick) with a partial linear crack up to half of the thickness of the plate with two boundary conditions: (i) all the sides simply supported (SSSS), and (ii) two adjacent sides clamped and the other two simply supported (CCSS) are taken for optimization. In this investigation, stacking sequence, crack length ratio, volume fraction, and length-width ratio have been considered design factors, while the thickness of the plate has been expected to be constant over the working field, and $\mathrm{L}_{27}$ orthogonal array was selected.

Table 2. Fundamental natural frequencies and their normalized for SSSS boundary conditions.

\begin{tabular}{l|l|l|l|l|l|l|l|l|l} 
Test Run & $\mathbf{a} / \mathbf{L}_{\mathbf{1}}$ & $\mathbf{V F}$ & $\mathbf{L}_{\mathbf{2}} / \mathbf{L}_{\mathbf{1}}$ & $\mathbf{0 / 9 0 / 0}$ & $\mathbf{3 0 / 9 0 / 3 0}$ & $\mathbf{4 5 / 9 0 / 4 5}$ & $\mathbf{N - 0 / 9 0 / 0}$ & $\mathbf{N - 3 0 / 9 0 / 3 0}$ & $\mathbf{N - 5 / 9 0 / 4 5}$ \\
\hline 1 & 0.00 & $0.6 / 0.6$ & 1.0 & 387.28 & 483.35 & 511.38 & 0.0000 & 0.0000 & 0.0000 \\
\hline 2 & 0.00 & $0.6 / 0.6$ & 1.5 & 376.77 & 422.72 & 420.30 & 0.1104 & 0.2847 & 0.3341 \\
\hline 3 & 0.00 & $0.6 / 0.6$ & 2.0 & 354.83 & 329.66 & 292.09 & 0.3409 & 0.7216 & 0.8044 \\
\hline 4 & 0.00 & $0.5 / 0.6$ & 1.0 & 354.91 & 442.73 & 468.36 & 0.3401 & 0.1907 & 0.1578
\end{tabular}




\begin{tabular}{l|l|l|l|l|l|l|l|l|l}
\hline Test Run & $\mathbf{a} / \mathbf{L}_{\mathbf{1}}$ & $\mathbf{V F}$ & $\mathbf{L} \mathbf{L}_{\mathbf{L}} \mathbf{1}$ & $\mathbf{0 / 9 0 / 0}$ & $\mathbf{3 0 / 9 0 / 3 0}$ & $\mathbf{4 5 / 9 0 / 4 5}$ & $\mathbf{N - 0 / 9 0 / 0}$ & $\mathbf{N - 3 0 / 9 0 / 3 0}$ & $\mathbf{N - 5 / 9 0 / 4 5}$ \\
\hline 5 & 0.00 & $0.5 / 0.6$ & 1.5 & 349.86 & 385.90 & 381.12 & 0.3931 & 0.4575 & 0.4778 \\
\hline 6 & 0.00 & $0.5 / 0.6$ & 2.0 & 324.86 & 301.72 & 267.21 & 0.6557 & 0.8528 & 0.8956 \\
\hline 7 & 0.00 & $0.4 / 0.6$ & 1.0 & 321.59 & 399.43 & 422.20 & 0.6901 & 0.3940 & 0.3271 \\
\hline 8 & 0.00 & $0.4 / 0.6$ & 1.5 & 301.44 & 319.57 & 311.24 & 0.9018 & 0.7690 & 0.7341 \\
\hline 9 & 0.00 & $0.4 / 0.6$ & 2.0 & 292.33 & 271.60 & 240.74 & 0.9975 & 0.9942 & 0.9927 \\
\hline 10 & 0.01 & $0.6 / 0.6$ & 1.0 & 387.10 & 482.94 & 510.73 & 0.0019 & 0.0019 & 0.0024 \\
\hline 11 & 0.01 & $0.6 / 0.6$ & 1.5 & 378.08 & 419.91 & 414.28 & 0.0966 & 0.2979 & 0.3562 \\
\hline 12 & 0.01 & $0.6 / 0.6$ & 2.0 & 354.76 & 329.25 & 291.43 & 0.3416 & 0.7235 & 0.8068 \\
\hline 13 & 0.01 & $0.5 / 0.6$ & 1.0 & 354.74 & 442.35 & 467.76 & 0.3418 & 0.1925 & 0.1600 \\
\hline 14 & 0.01 & $0.5 / 0.6$ & 1.5 & 347.49 & 380.94 & 374.32 & 0.4180 & 0.4808 & 0.5027 \\
\hline 15 & 0.01 & $0.5 / 0.6$ & 2.0 & 324.79 & 301.35 & 266.61 & 0.6565 & 0.8545 & 0.8978 \\
\hline 16 & 0.01 & $0.4 / 0.6$ & 1.0 & 321.42 & 399.08 & 421.66 & 0.6919 & 0.3957 & 0.3291 \\
\hline 17 & 0.01 & $0.4 / 0.6$ & 1.5 & 298.89 & 315.52 & 306.64 & 0.9286 & 0.7880 & 0.7510 \\
\hline 19 & 0.01 & $0.4 / 0.6$ & 2.0 & 292.26 & 271.26 & 240.19 & 0.9982 & 0.9958 & 0.9947 \\
\hline 20 & 0.05 & $0.6 / 0.6$ & 1.0 & 386.62 & 481.85 & 509.02 & 0.0069 & 0.0070 & 0.0087 \\
\hline 21 & 0.05 & $0.6 / 0.6$ & 1.5 & 371.82 & 379.90 & 354.42 & 0.1624 & 0.4857 & 0.5757 \\
\hline 22 & 0.05 & $0.6 / 0.6$ & 2.0 & 354.58 & 328.19 & 289.70 & 0.3435 & 0.7285 & 0.8131 \\
\hline 23 & 0.05 & $0.5 / 0.6$ & 1.0 & 354.29 & 441.34 & 466.18 & 0.3466 & 0.1972 & 0.1658 \\
\hline 24 & 0.05 & $0.5 / 0.6$ & 1.5 & 326.86 & 331.66 & 311.40 & 0.6347 & 0.7122 & 0.7335 \\
\hline 25 & 0.05 & $0.5 / 0.6$ & 2.0 & 324.62 & 300.36 & 265.01 & 0.6583 & 0.8591 & 0.9037 \\
\hline 26 & 0.05 & $0.4 / 0.6$ & 1.0 & 320.97 & 398.15 & 420.22 & 0.6966 & 0.4000 & 0.3344 \\
\hline 27 & 0.05 & $0.4 / 0.6$ & 1.5 & 295.29 & 297.24 & 280.48 & 0.9664 & 0.8738 & 0.8469 \\
\hline & 0.05 & $0.4 / 0.6$ & 2.0 & 292.09 & 270.36 & 238.75 & 1.0000 & 1.0000 & 1.0000
\end{tabular}

Table 2 indicates the response and normalized value using Eqns. 20 \& 21 for different stacking sequences for the first boundary condition (SSSS). The results are calculated by varying the crack length, the volume of the fraction of fibers, and the dimensions of the plate. The results show that the natural frequency decreases with an increase in the crack-length ratio, length-width ratio, and decrease in volume of the fraction.

From the normalized value of each performance from each run, the grey relational coefficient has been calculated using Eqn. 22 \& 23 for each performance parameter against each set of runs, as shown in Table 3. In this table, the value of overall grey is calculated by Eqn. 24.

Table 3. Value of individual grey and overall grey for SSSS boundary condition.

\begin{tabular}{l|l|l|l|c} 
Test Run & Grey 1 & Grey 2 & Grey 3 & Overall Grey \\
\hline 1 & 0.3333 & 0.3333 & 0.3333 & 0.3333 \\
\hline 2 & 0.4069 & 0.5231 & 0.5561 & 0.4954 \\
\hline 3 & 0.5606 & 0.8144 & 0.8696 & 0.7482 \\
\hline 4 & 0.5600 & 0.4605 & 0.4385 & 0.4863 \\
\hline 5 & 0.5954 & 0.6384 & 0.6519 & 0.6285 \\
\hline 6 & 0.7705 & 0.9018 & 0.9304 & 0.8676 \\
\hline 7 & 0.7934 & 0.5960 & 0.5514 & 0.6469 \\
\hline 8 & 0.9345 & 0.8460 & 0.8227 & 0.9965 \\
\hline 9 & 0.9983 & 0.9961 & 0.9951 & 0.3347 \\
\hline 10 & 0.3346 & 0.3346 & 0.3349 & 0.5001 \\
\hline 11 & 0.3978 & 0.5319 & 0.5708 & 0.7493 \\
\hline 13 & 0.5611 & 0.8157 & 0.8712 & 0.4876 \\
\hline 14 & 0.5612 & 0.4617 & 0.4400 & 0.6448 \\
\hline 15 & 0.6120 & 0.6539 & 0.6685 & 0.8686 \\
\hline 17 & 0.7710 & 0.9030 & 0.9319 & 0.8817 \\
\hline 18 & 0.7946 & 0.5971 & 0.5527 & 0.9975 \\
\hline 19 & 0.9524 & 0.8586 & 0.8340 & 0.3384 \\
\hline 21 & 0.9988 & 0.9972 & 0.9965 & 0.6053 \\
\hline 22 & 0.3380 & 0.3380 & 0.3391 & 0.7523 \\
\hline 23 & 0.4416 & 0.6571 & 0.7172 & 0.4910 \\
\hline 25 & 0.5623 & 0.8190 & 0.8754 & 0.7957 \\
\hline & 0.5644 & 0.4648 & 0.4439 & 0.8714 \\
\hline
\end{tabular}




\begin{tabular}{l|c|c|c|c} 
Test Run & Grey 1 & Grey 2 & Grey 3 & Overall Grey \\
\hline 26 & 0.9776 & 0.9159 & 0.8980 & 0.9305 \\
\hline 27 & 1.0000 & 1.0000 & 1.0000 & 1.0000
\end{tabular}

Table 4. Fundamental natural frequencies and their normalized for CCSS boundary condition.

\begin{tabular}{l|c|c|c|c|c|c|c|c|c} 
Test Run & $\mathbf{a} / \mathbf{L}_{\mathbf{1}}$ & $\begin{array}{c}\text { Volume } \\
\text { fraction }\end{array}$ & $\mathbf{L}_{\mathbf{2}} / \mathbf{L}_{\mathbf{1}}$ & $\mathbf{0 / 9 0 / 0}$ & $\mathbf{3 0 / 9 0 / 3 0}$ & $\mathbf{4 5 / 9 0 / 4 5}$ & $\mathbf{N - 0 / 9 0 / 0}$ & $\mathbf{N - 0 / 9 0 / 3 0}$ & $\mathbf{N - 5 / 9 0 / 4 5}$ \\
\hline 1 & 0.00 & $0.6 / 0.6$ & 1.0 & 606.35 & 674.82 & 696.15 & 0.0000 & 0.0000 & 0.0000 \\
\hline 2 & 0.00 & $0.6 / 0.6$ & 1.5 & 143.14 & 135.24 & 123.06 & 0.9376 & 0.9365 & 0.9357 \\
\hline 3 & 0.00 & $0.6 / 0.6$ & 2.0 & 141.14 & 123.15 & 103.75 & 0.9416 & 0.9575 & 0.9672 \\
\hline 4 & 0.00 & $0.5 / 0.6$ & 1.0 & 555.92 & 618.33 & 637.77 & 0.1021 & 0.0980 & 0.0953 \\
\hline 5 & 0.00 & $0.5 / 0.6$ & 1.5 & 131.08 & 123.81 & 112.62 & 0.9620 & 0.9563 & 0.9527 \\
\hline 6 & 0.00 & $0.5 / 0.6$ & 2.0 & 129.18 & 112.72 & 94.91 & 0.9659 & 0.9756 & 0.9816 \\
\hline 7 & 0.00 & $0.4 / 0.6$ & 1.0 & 503.26 & 558.36 & 575.55 & 0.2087 & 0.2021 & 0.1969 \\
\hline 8 & 0.00 & $0.4 / 0.6$ & 1.5 & 118.05 & 111.53 & 101.52 & 0.9884 & 0.9776 & 0.9708 \\
\hline 9 & 0.00 & $0.4 / 0.6$ & 2.0 & 116.20 & 101.47 & 85.56 & 0.9921 & 0.9951 & 0.9969 \\
\hline 10 & 0.01 & $0.6 / 0.6$ & 1.0 & 606.21 & 674.46 & 695.56 & 0.0003 & 0.0006 & 0.0010 \\
\hline 11 & 0.01 & $0.6 / 0.6$ & 1.5 & 141.86 & 134.34 & 122.45 & 0.9402 & 0.9380 & 0.9367 \\
\hline 12 & 0.01 & $0.6 / 0.6$ & 2.0 & 139.80 & 122.21 & 103.12 & 0.9444 & 0.9591 & 0.9682 \\
\hline 13 & 0.01 & $0.5 / 0.6$ & 1.0 & 555.78 & 617.99 & 637.23 & 0.1024 & 0.0986 & 0.0962 \\
\hline 14 & 0.01 & $0.5 / 0.6$ & 1.5 & 129.91 & 122.98 & 112.06 & 0.9644 & 0.9578 & 0.9536 \\
\hline 15 & 0.01 & $0.5 / 0.6$ & 2.0 & 128.00 & 111.86 & 94.33 & 0.9682 & 0.9771 & 0.9826 \\
\hline 16 & 0.01 & $0.4 / 0.6$ & 1.0 & 503.13 & 558.04 & 575.05 & 0.2089 & 0.2027 & 0.1977 \\
\hline 17 & 0.01 & $0.4 / 0.6$ & 1.5 & 117.01 & 110.79 & 101.02 & 0.9905 & 0.9789 & 0.9716 \\
\hline 18 & 0.01 & $0.4 / 0.6$ & 2.0 & 115.14 & 100.70 & 85.04 & 0.9943 & 0.9964 & 0.9977 \\
\hline 20 & 0.05 & $0.6 / 0.6$ & 1.0 & 605.83 & 673.48 & 693.98 & 0.0011 & 0.0023 & 0.0035 \\
\hline 21 & 0.05 & $0.6 / 0.6$ & 1.5 & 138.46 & 131.93 & 120.84 & 0.9471 & 0.9422 & 0.9393 \\
\hline 22 & 0.05 & $0.6 / 0.6$ & 2.0 & 136.36 & 119.70 & 101.44 & 0.9513 & 0.9634 & 0.9710 \\
\hline 23 & 0.05 & $0.5 / 0.6$ & 1.0 & 555.43 & 617.08 & 635.77 & 0.1031 & 0.1002 & 0.0986 \\
\hline 24 & 0.05 & $0.5 / 0.6$ & 1.5 & 126.80 & 120.78 & 110.60 & 0.9707 & 0.9616 & 0.9560 \\
\hline 25 & 0.05 & $0.5 / 0.6$ & 2.0 & 124.85 & 109.56 & 92.79 & 0.9746 & 0.9810 & 0.9851 \\
\hline 26 & 0.05 & $0.4 / 0.6$ & 1.0 & 502.77 & 557.21 & 573.73 & 0.2097 & 0.2041 & 0.1999 \\
\hline 27 & 0.05 & $0.4 / 0.6$ & 1.5 & 114.21 & 108.80 & 99.70 & 0.9962 & 0.9824 & 0.9738 \\
\hline & 0.05 & $0.4 / 0.6$ & 2.0 & 112.31 & 98.64 & 83.65 & 1.0000 & 1.0000 & 1.0000
\end{tabular}

Table 4 indicates the response and normalized value using Eqns. 20-21 for different stacking sequences for second boundary condition (CCSS). The results are calculated by varying the crack length, the volume of the fraction of fibers, and the dimensions of the plate. From the normalized value of each performance from each run, the grey relational coefficient has been calculated using Eqns. 22-23 for each performance parameter against each set of runs, as shown in Table 5. In this table, the value of overall grey is calculated by Eqns. 24.

Table 5. Value of individual and overall grey for CCSS boundary condition.

\begin{tabular}{l|l|l|l|c} 
Test Run & Grey 1 & Grey 2 & Grey 3 & Overall Grey \\
\hline 1 & 0.3333 & 0.3333 & 0.3333 & 0.3333 \\
\hline 2 & 0.8890 & 0.8873 & 0.8860 & 0.8874 \\
\hline 3 & 0.8955 & 0.9216 & 0.9384 & 0.9185 \\
\hline 4 & 0.3577 & 0.3566 & 0.3560 & 0.3568 \\
\hline 5 & 0.9294 & 0.9197 & 0.9136 & 0.9209 \\
\hline 6 & 0.9361 & 0.9534 & 0.9645 & 0.9513 \\
\hline 7 & 0.3872 & 0.3852 & 0.3837 & 0.3854 \\
\hline 8 & 0.9773 & 0.9572 & 0.9449 & 0.9598 \\
\hline 9 & 0.9845 & 0.9903 & 0.9938 & 0.9895 \\
\hline 10 & 0.3334 & 0.3335 & 0.3335 & 0.3335 \\
\hline 11 & 0.8932 & 0.8897 & 0.8876 & 0.8902 \\
\hline 12 & 0.8999 & 0.9244 & 0.9402 & 0.9215 \\
\hline 13 & 0.3577 & 0.3568 & 0.3562 & 0.3569 \\
\hline 15 & 0.9335 & 0.9221 & 0.9151 & 0.9236 \\
\hline 16 & 0.9403 & 0.9561 & 0.9663 & 0.9542 \\
\hline 17 & 0.3873 & 0.3854 & 0.3839 & 0.3855 \\
\hline 18 & 0.9813 & 0.9595 & 0.9463 & 0.9624 \\
\hline 20 & 0.9887 & 0.9929 & 0.9955 & 0.9924 \\
\hline 19 & 0.3336 & 0.3339 & 0.3341 & 0.3338 \\
\hline
\end{tabular}




\begin{tabular}{l|l|l|l|c}
\hline Test Run & Grey 1 & Grey 2 & Grey 3 & Overall Grey \\
\hline 21 & 0.9113 & 0.9319 & 0.9451 & 0.9294 \\
\hline 22 & 0.3579 & 0.3572 & 0.3568 & 0.3573 \\
\hline 23 & 0.9446 & 0.9286 & 0.9191 & 0.9308 \\
\hline 24 & 0.9517 & 0.9635 & 0.9710 & 0.9621 \\
\hline 25 & 0.3875 & 0.3858 & 0.3846 & 0.3860 \\
\hline 26 & 0.9924 & 0.9659 & 0.9502 & 0.9695 \\
\hline 27 & 1.0000 & 1.0000 & 1.0000 & 1.0000
\end{tabular}

The following response table for Grey relational analysis has been created from the Grade values as shown in Table 3 and Table 5. The value of natural frequency has been obtained using CLPT, and after that, optimization has been done using grey based Taguchi approach.

Table 6. Grey relational analysis response table for the signal to noise ratio (larger is better) for SSSS boundary condition.

\begin{tabular}{l|c|c|c} 
Level & $\mathbf{A}$ & $\mathbf{B}$ & $\mathbf{C}$ \\
\hline $\mathbf{1}$ & -3.860 & -1.586 & -6.490 \\
\hline $\mathbf{2}$ & -3.799 & -3.573 & -3.251 \\
\hline $\mathbf{3}$ & -3.328 & -5.827 & -1.245 \\
\hline Delta & 0.531 & 4.240 & 5.245 \\
\hline Rank & 3 & 2 & 1
\end{tabular}

Table 7. Grey relational analysis response table for the signal to noise ratio (larger is better) for CCSS boundary condition.

\begin{tabular}{l|c|c|c} 
Level & $\mathbf{A}$ & $\mathbf{B}$ & $\mathbf{C}$ \\
\hline $\mathbf{1}$ & -3.3500 & -2.8829 & -8.9201 \\
\hline $\mathbf{2}$ & -3.3316 & -3.3385 & -0.6640 \\
\hline $\mathbf{3}$ & -3.2823 & -3.7425 & -0.3799 \\
\hline Delta & 0.0677 & 0.8596 & 8.5402 \\
\hline Rank & 3 & 2 & 1
\end{tabular}

From these responses (Table 6 and Table 7), it is clear that the maximum influence on the best combination of all input variables in $C$, i.e., a ratio of length width $\left(\mathrm{L}_{2} / \mathrm{L}_{1}\right)$. The graphical representation of the effect of the input variable is also shown in Figure 4 and Figure 5.

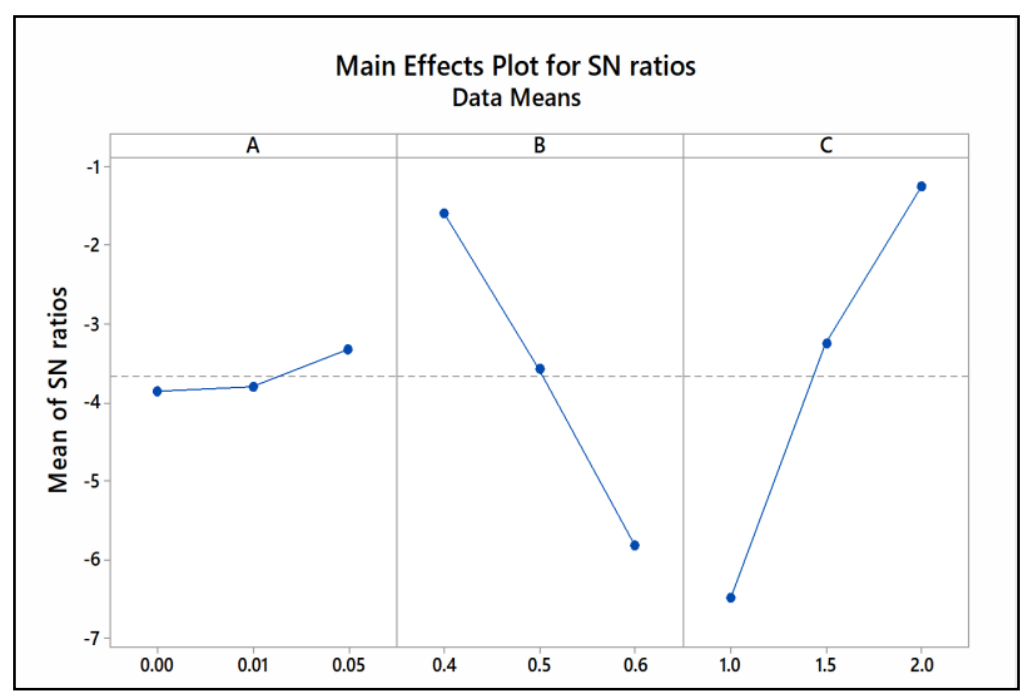

Figure 4. Response graph of input variable in grey relational analysis for SSSS boundary condition. 


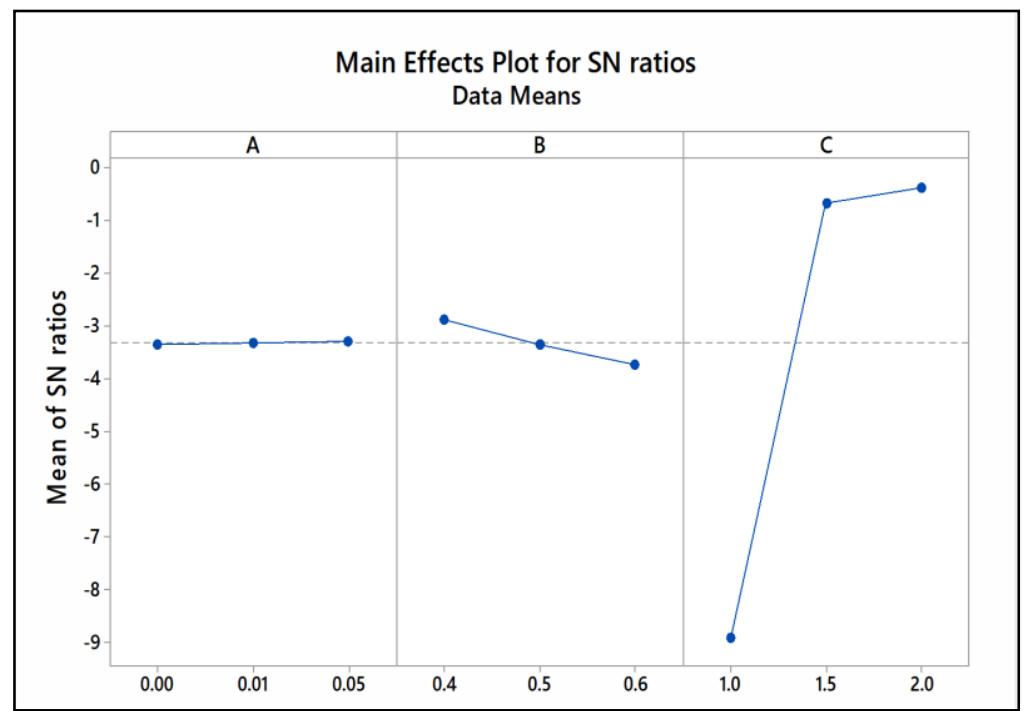

Figure 5. Response graph of input variable in grey relational analysis for CCSS boundary condition.

The desired weighted grey relational grade (GRG) for each order is considered an output response for the additional analysis. In this work, better quality properties have been used to analyze GRG because it indicates the superior performance of a larger value process. The number of recurrence tests is the same as only one relational grade should be achieved in each group for this special determination of $\mathrm{S} / \mathrm{N}$. The mean effects plot for the $\mathrm{S} / \mathrm{N}$ ratio for both the boundary conditions is shown in the graph (Figs. $4 \& 5$ ).

After determining the optimum conditions, a confirmation test is to be done to check the responses obtained from the Grey Taguchi analysis.

Table 8. Confirmation test for results of SSSS and CCSS boundary conditions.

\begin{tabular}{l|l|l|l|l|l|l}
\multirow{2}{*}{ Boundary Conditions } & \multicolumn{2}{|l}{ Initial Test Run } & Predicted & \multicolumn{2}{l}{ After Optimized } \\
\cline { 2 - 7 } & Sequence & Grade & Sequence & Grade & Sequence & Grade \\
\hline SSSS & A1B1C1 & 0.3333 & - & 1.0 & A3B1C3 & 1.0 \\
\hline CCSS & A1B1C1 & 0.3333 & - & 1.0 & A3B1C3 & 1.0
\end{tabular}

From the above optimization (Table 6 and Table 8) and confirmation test (Table 8), it is obtained that the $45^{\circ} / 90^{\circ} / 45^{\circ}$ stacking sequence provides a maximum optimum response. This work concludes that the optimum level to manufacture composite laminated plates is $\mathrm{A} 3 \mathrm{~B} 1 \mathrm{C} 3$, with the highest-grade value of 1.0. From this work, the crack length ratio is 0.05 , the fraction volume is $0.4 / 0.6$, and the length-width ratios 2.0 optimum input variables are obtained.

\section{Conclusions}

Vibrations of the partially cracked composite plate with two boundary conditions are analyzed. The incremental crack growth (middle of the plate) reliability of the hybrid composite is explored. A mathematical model has been developed using classical laminated plate theory to evaluate the natural frequency for both SSSS) and CCSS. Grey relation analysis has also been applied to optimize the parameters. The maximum importance is found in the optimum combination A3B1C3. Subsequently, an attempt is made to optimize the natural vibration, considering three parameters, i.e., stacking sequence, crack length, and volume fraction. It was found that it is minimum for the $45^{\circ} / 90^{\circ} / 45^{\circ}$ laminate and decreases with the decrease in volume fraction. The natural frequency is affected due to the length ratio; it decreases with an increase in the length-width ratio. It also depends on an increase in the crack 
length and a decrease in volume fraction; the presence of $45^{\circ}$ fiber orientation provides an optimum response. Finally, it can be said that the Taguchi-Grey relational analysis technique has provided a systematic and efficient method for optimization of the design of hybrid laminated composite plates, which take comparatively less time in the analysis.

\section{Funding}

The authors do not receive any form of financial support from any organization and individuals.

\section{Acknowledgments}

The authors are heartily thankful to Shri Shankaracharya Group of Institutions, Bhilai, for providing infrastructural support for carrying out the present research work.

\section{Conflicts of Interest}

The authors declare no conflict of interest.

\section{References}

1. Reissner, E.; Stavsky, Y. Bending and stretching of certain types of heterogeneous isotropic elastic plates. ASME J. Appl. Mech. 1961, 28, 402-408, https://doi.org/10.1115/1.3641719.

2. Timoshenko, S.P.; Woinowsky-Krieger, S. Theory of plates and shells. New York: Mc-Graw Hill, 1959.

3. Szilard, R. Theory and Analysis of Plates. Prentice-Hall, Englewood Cliffs, New Jersy, 1974.

4. Bement, T.R. Taguchi Techniques for Quality Engineering. Volume 31, 2. McGraw-Hill, 1989.

5. Senthilkumar, N.; Ganapathy, T.; Tamizharasan, T. Optimisation of machining and geometrical parameters in turning process using Taguchi method. Australian Journal of Mechanical Engineering 2014, 12, 233-246, https://doi.org/10.7158/M12-113.2014.12.2.

6. Julong, D. Introduction to grey system theory. The Journal of grey system 1989, 1, 1-24.

7. Lin, J.L.; Tarng, Y.S. Optimization of the multi-response process by the Taguchi method with grey relational analysis. Journal of Grey system 1998, 4, 355-370.

8. Venkateswarlu, S.; Suresh, R.K.; Dileep, P. Analysis and Optimization of Process Parameters During Boring Process. Int. J. Inf. Futur. Res. 2015, 3, 834-843.

9. Hsiao, Y.F.; Tarng, Y.S.; Huang, W.J. Optimization of Plasma Arc Welding Parameters by Using the Taguchi Method with the Grey Relational Analysis. Materials and Manufacturing Processes 2007, 23, 51-58, https://doi.org/10.1080/10426910701524527.

10. K Abhishek, K.; Datta, S.; Mahapatra, S.S. Optimization of thrust, torque, entry, and exist delamination factor during drilling of CFRP composites. The International Journal of Advanced Manufacturing Technology 2015, 76, 401-416, https://doi.org/10.1007/s00170-014-6199-3.

11. Rahul, K. Abhishek, K.; Datta, S.; Biswal, B.B.; Mahapatra, S.S. Machining performance optimization for electro-discharge machining of Inconel 601, 625, 718 and 825: an integrated optimization route combining satisfaction function, fuzzy inference system and Taguchi approach. Journal of the Brazilian Society of Mechanical Sciences and Engineering 2017, 39, 3499-3527, http://dx.doi.org/10.1007/s40430-016-0659-7.

12. Rajyalakshmi, G.; Venkata Ramaiah, P. Multiple process parameter optimization of wire electrical discharge machining on Inconel 825 using Taguchi grey relational analysis. The International Journal of Advanced Manufacturing Technology 2013, 69, 1249-1262, https://doi.org/10.1007/s00170-013-5081-z.

13. Köklü, U. Optimisation of machining parameters in interrupted cylindrical grinding using the Grey-based Taguchi method. International Journal of Computer Integrated Manufacturing 2013, 26, 696-702, https://doi.org/10.1080/0951192X.2012.749537.

14. Saikumar, V.; Venkatesh, V.; Sivaiah, P. Multi-objective optimization in CNC milling process of Al-Cu-Zn alloy matrix composite by using Taguchi-grey relational analysis technique. Advanced Materials Manufacturing \& Characterization 2015, 5, 35-42, http://dx.doi.org/10.11127/ijammc.2015.03.05.

15. Singaravel, B.; Selvaraj, T. Application of Taguchi method for optimization of parameters in turning operation. Journal for Manufacturing Science and Production 2016, 16, 183-187, https://doi.org/10.1515/jmsp-2016-0004.

16. Sivasakthivel, P.S.; Sudhakaran, R.; Rajeswari, S. Optimization of machining parameters to minimize vibration amplitude while machining Al 6063 using gray-based Taguchi method. Proceedings of the Institution of Mechanical Engineers, Part B: Journal of Engineering Manufacture 2013, 227, 1788-1799, http://dx.doi.org/10.1177/0954405413494921. 
17. Joshi, P.V.; Jain, N.K.; Ramtekkar, G.D. Analytical modeling for vibration analysis of thin rectangular orthotropic/functionally graded plates with an internal crack. Journal of Sound and Vibration 2015, 344, 377 398, http://dx.doi.org/10.1016/j.jsv.2015.01.026.

18. Israr, A.; Cartmell, M.P.; Manoach, E.; Trendafilova, I.; Ostachowicz, W.; Krawczuk, M.; Żak, A. Analytical modeling and vibration analysis of partially cracked rectangular plates with different boundary conditions and loading. Journal of Applied Mechanics 2009, 76, https://doi.org/10.1115/1.2998755.

19. Ismail, R.; Cartmell, M.P. An investigation into the vibration analysis of a plate with a surface crack of variable angular orientation. Journal of Sound and Vibration 2012, 331, 2929-2948, https://doi.org/10.1016/j.jsv.2012.02.011.

20. Joshi, P.V.; Jain, N.K.; Ramtekkar, G.D. Analytical modeling and vibration analysis of internally cracked rectangular plates. Journal of Sound and Vibration 2014, 333, 5851-5864, https://doi.org/10.1016/j.jsv.2014.06.028.

21. Joshi, P.V.; Jain, N.K.; Ramtekkar, G.D. Analytical modelling for vibration analysis of partially cracked orthotropic rectangular plates. European Journal of Mechanics - A/Solids 2015, 50, 100-111, https://doi.org/10.1016/j.euromechsol.2014.11.007.

22. Jones, R.M. Mechanics of Composite Materials. Second. CRC Press, 1998.

23. Nayfeh, A.H. Perturbation Methods. Wiley online Library, New York, 1973; https://doi.org/10.1002/9783527617609.

24. Murdock, J.A. Perturbations: Theory and Methods. SIAM, 1999.

25. Kim, H.H.; Babu, J.S.S.; Kang, C.G. Fabrication of A356 aluminum alloy matrix composite with CNTs/A12O3 hybrid reinforcements. Materials Science and Engineering: A 2020, 573, 92-99, https://doi.org/10.1016/j.msea.2013.02.041.

26. Basariya, M.R.; Srivastava, V.C.; Mukhopadhyay, N.K. Microstructural characteristics and mechanical properties of carbon nanotube reinforced aluminum alloy composites produced by ball milling. Materials \& Design 2014, 64, 542-549, https://doi.org/10.1016/j.matdes.2014.08.019.

27. Wang, A.; Chen, H.; Hao, Y.; Zhang, W. Vibration and bending behavior of functionally graded nanocomposite doubly-curved shallow shells reinforced by graphene nanoplatelets. Results in Physics 2018, 9, 550-559, https://doi.org/10.1016/j.rinp.2018.02.062.

28. Wang, M.; Xu, Y.G.; Qiao, P.; Li, Z.M. A two-dimensional elasticity model for bending and free vibration analysis of laminated graphene-reinforced composite beams. Composite Structures 2019, 211, 364-375, https://doi.org/10.1016/j.compstruct.2018.12.033.

29. Safaei, B.; Ahmed, N.A.; Fattahi, A.M. Free vibration analysis of polyethylene/CNT plates. The European Physical Journal Plus 2019, 134, 271, https://doi.org/10.1140/epjp/i2019-12650-x.

30. Sirajudheen, P.; Nikitha, M.R.; Karthikeyan, P.; Meenakshi, S. Perceptive removal of toxic azo dyes from water using magnetic $\mathrm{Fe} 3 \mathrm{O} 4$ reinforced graphene oxide-carboxymethyl cellulose recyclable composite: Adsorption investigation of parametric studies and their mechanisms. Surfaces and Interfaces. 2020, 21, 100648, https://doi.org/10.1016/j.surfin.2020.100648.

31. Kang, H.; Kwon, S.H.; Lawler, R.; Lee, J.H.; Doo, G.; Kim, H.-T.; Yim, S.-D.; Jang, S.S.; Lee, S.G. Nanostructures of Nafion Film at Platinum/Carbon Surface in Catalyst Layer of PEMFC: Molecular Dynamics Simulation Approach. The Journal of Physical Chemistry C. 2020, 124, 21386-21395, https://doi.org/10.1021/acs.jpcc.0c03651.

32. Chaudhary, V.; Bajpai, P.K.; Maheshwari, S. Effect of moisture absorption on the mechanical performance of natural fiber reinforced woven hybrid bio-composites. J. Nat. Fibers 2020, 17, 84-100, https://doi.org/10.1080/15440478.2018.1469451.

33. Moradnia, F.; Taghavi Fardood, S.; Ramazani, A.; Gupta, V.K. Green synthesis of recyclable MgFeCrO4 spinel nanoparticles for rapid photodegradation of direct black 122 dye. Journal of Photochemistry and Photobiology A: Chemistry 2020, 392, https://doi.org/10.1016/j.jphotochem.2020.112433.

34. Ghaztar, M.M.M.; Romli, A.Z.; Ibrahim, N. The effect of viscosities of various coating solutions on the physical, mechanical and morphological properties of kenaf/epoxy composites. Biointerface Research in Applied Chemistry 2020, 10, 5660-5664, doi:10.33263/briac103.660664.

35. Farrash, S.M.H.; Shariati, M.; Rezaeepazhand, J. The effect of carbon nanotube dispersion on the dynamic characteristics of unidirectional hybrid composites: An experimental approach. Composites Part B: Engineering 2017, 122, 1-8, https://doi.org/10.1016/j.compositesb.2017.04.003.

36. Reddy, R.M.R.; Karunasena, W.; Lokuge, W. Free vibration of functionally graded-GPL reinforced composite plates with different boundary conditions. Aerospace Science and Technology 2018, 78, 147-156, https://doi.org/10.1016/j.ast.2018.04.019.

37. Verma, M., Verma, A. K., \& Kumhar, V. Evaluation of Ultimate Strength and Fundamental Frequency of Fiber/Epoxy and Fiber/Al6061 Composite Plate. Biointerface Research in Applied Chemistry 2021, 12-3, 3390 - 3406, https://doi.org/10.33263/BRIAC123.33903406.

38. Lai S.K., Zhang L.H. Free Vibration Analysis of Cracked Orthotropic Rectangular Plates Under Thermal Effect. In: Wang C., Ho J., Kitipornchai S. (eds) ACMSM25. Lecture Notes in Civil Engineering $2020,37$. https://doi.org/10.1007/978-981-13-7603-0_23 
39. Van Do, V.N., Lee, CH. Isogeometric layerwise formulation for bending and free vibration analysis of laminated composite plates. Acta Mech 2021, 232, 1329-1351 . https://doi.org/10.1007/s00707-020-029007

40. Wang, D., Wu, Y., Wang, J., Hui, J., Zhang, B., \& Cao, W. Post-buckling path and free vibration of a symmetric laminated plate vertically coupled with fluid under in-plane load. Composite Structures 2021, 275 , 114433. https://doi.org/10.1016/j.compstruct.2021.114433

41. Jain, N. K., Soni, S., \& Prajapati, R. Analytical treatment for vibration analysis of partially cracked orthotropic and FGM submerged cylindrical shell with consideration of fluid-structure interaction. Mechanics Based Design of Structures and Machines 2021, 49(4), 463-486. https://doi.org/10.1080/15397734.2019.1689140

42. Xu, C., Rong, D., Zhou, Z., Deng, Z., \& Lim, C. W. Vibration and buckling characteristics of cracked natural fiber reinforced composite plates with corner point-supports. Engineering Structures 2020, 214, 110614. https://doi.org/10.1016/j.engstruct.2020.110614

43. Ghasemi, A.R., Heidari-Rarani, M., Heidari-Sheibani, B. et al. Free transverse vibration analysis of laminated composite beams with arbitrary number of concentrated masses. Arch Appl Mech 2021, 91, 2393-2402 https://doi.org/10.1007/s00419-021-01924-2

44. Ardic I., Yildizdag M., Ergin A. An FE-BE Method for the Hydroelastic Vibration Analysis of Plates and Shells Partially in Contact with Fluid. In: Abali B., Giorgio I. (eds) Developments and Novel Approaches in Nonlinear Solid Body Mechanics. Advanced Structured Materials 2020, 130. https://doi.org/10.1007/978-3030-50460-1_16

45. Karimi, M., Khorshidi, K., Dimitri, R., \& Tornabene, F. Size-dependent hydroelastic vibration of FG microplates partially in contact with a fluid. Composite Structures 2020, 244, 112320. https://doi.org/10.1016/j.compstruct.2020.112320. 